\title{
ASOCIACIÓN DE CARCINOMA RENAL Y LA EXPOSICIÓN A RADIACIONES IONIZANTES DESPUÉS DEL ACCIDENTE DE CHERNOBYL
}

\author{
A. BLANCO ESPINOSA, M. LEVA VALLEJO, F. MERLO DE LA PEÑA*, \\ P. MORENO ARCAS, J.L. CARAZO CARAZO, M.J. REQUENA TAPIA \\ Servicio de Urología. *Unidad de Investigación. Hospital Regional Universitario Reina Sofía. Córdoba. \\ Actas Urol Esp. 27 (2): 164-167, 2003
}

\section{RESUMEN}

“ASOCIACIÓN DE CARCINOMA RENAL Y LA EXPOSICIÓN A RADIACIONES IONIZANTES DESPUÉS DEL ACCIDENTE DE CHERNOBYL"

Después del accidente nuclear de Chernobyl, en la población de zonas contaminadas la incidencia de carcinoma renal se incrementó de 4,7 a 7,5 por 100.000 habitantes. La elevada concentración corporal de Cesium $137\left({ }^{137} \mathrm{Cs}\right)$ así como su eliminación por vía renal los convierte en pacientes de alto riesgo. Presentamos un caso de una paciente, residente en la zona contaminada que acudió a nuestro hospital por dolor abdominal y sensación de masa en flanco izquierdo. Realizamos una revisión de la literatura y analizamos el manejo en este tipo de pacientes.

PALABRAS CLAVE: Carcinoma renal. Radiación. Chernobyl.

\section{ABSTRACT \\ “ASSOCIATION OF RENAL CELL CARCINOMA AND RADIATION EXPOSURE AFTER THE CHERNOBYL ACCIDENT"}

After the nuclear accident of Chernobyl, in the population of zones contaminated the malignant renal tumors was increased from 4,7 to 7,5 per 100.000 of total population. Cesium $137\left({ }^{137} \mathrm{Cs}\right)$ constitutes $80-$ $90 \%$ of the internal exposure of these people as well as eliminated through kidneys becomes an important risk factor. We present a case of a patient, residing in radiocontamined area, who consulted for abdominal pain and left flank mass. We review relevant literature and the management of these patients.

KEY WORDS: Renal cell carcinoma. Radiation. Chernobyl.

$\mathrm{L}$ os tumores malignos del parénquima renal suponen alrededor del $2 \%$ de todos los nuevos casos de cáncer y de muerte por año, con un rango entre 20.000 y 30.000 nuevos casos al año, tanto en la Unión Europea como en los Estados Unidos de América. Aparece tanto de forma esporádica como hereditaria y su etiología sigue siendo un enigma. No obstante, varios factores ambientales, ocupacionales, hormonales, celulares y genéticos se pueden considerar como influyentes en el desarrollo de esta neoplasia.
No existe una estricta asociación entre el carcinoma renal y la exposición a radiaciones ionizantes. Actualmente no existe una evidencia clara de que estos tumores sean inducidos por la radiación.

Después de los efectos radiactivos como consecuencia de los ataques atómicos de Hiroshima y Nagasaki se realizaron varios estudios que intentaron evidenciar la relación de la exposición a radiaciones con el incremento de mayor tasa de tumores sólidos. Estos estudios estimaron que el $22,5 \%$ de los supervivientes tenían más riesgo de desarrollar tumores sólidos. 
El accidente nuclear de Chernobyl en Ucrania, en abril de 1986 tuvo como consecuencia la exposición a radiaciones ionizantes a la población del área. El Cesium $137\left({ }^{137} \mathrm{Cs}\right)$ constituye el 80-90\% de la exposición de esta población. Muchos elementos radiactivos "simulan" minerales necesarios para el organismo, en este caso se comporta como el potasio, incorporándose rápidamente al organismo por la ingesta de alimentos contaminados. Este radionúclido se concentra y elimina por vía renal y el $90 \%$ de su forma más lábil se excreta por vía urinaria ${ }^{2}$.

El presente trabajo aporta el caso clínico de una paciente ucraniana residente en la zona en el momento del accidente que acudió a nuestro hospital por dolor abdominal y sensación de masa en flanco izquierdo.

\section{CASO CLÍNICO}

Paciente mujer de 42 años, de origen ucraniano, residente en España desde hace 1 año. Entre sus antecedentes personales destacaba la posibilidad de haber estado expuesta a las radiaciones ionizantes como consecuencia del accidente nuclear de Chernobyl, en abril de 1986, debido a que residía en la zona en aquella época.

Ingresada en la planta de hospitalización de medicina interna por un síndrome diarreico. En una primera exploración destacó a la exploración abdominal la palpación de una masa a nivel de flanco izquierdo que se desplazaba con facilidad, no siendo dolorosa y sin acompañarse de sintomatología urológica alguna. Presentaba una leve anemia (hemoglobina: $11 \mathrm{~g} / \mathrm{dl}$ ), siendo el resto de la analítica normal. En la radiografía simple de abdomen se objetivó una imagen redondeada totalmente calcificada, proyectada sobre la silueta renal izquierda de aprox. $8 \mathrm{~cm}$ (Fig. 1).

En base a la exploración física y ante los hallazgos radiológicos se solicitó una ecografía abdominal, donde se evidenció una masa de predominio quístico completamente calcificada con focos ecogénicos en su interior, diagnosticada de quiste complicado. La realización de una TAC abdominal puso de manifiesto la heterogeinidad de la masa encuadrándose en la clasificación de Bosniak como tipo II (Fig. 2).

Se decidió abordaje quirúrgico de la masa renal, evidenciándose una formación quística exo-

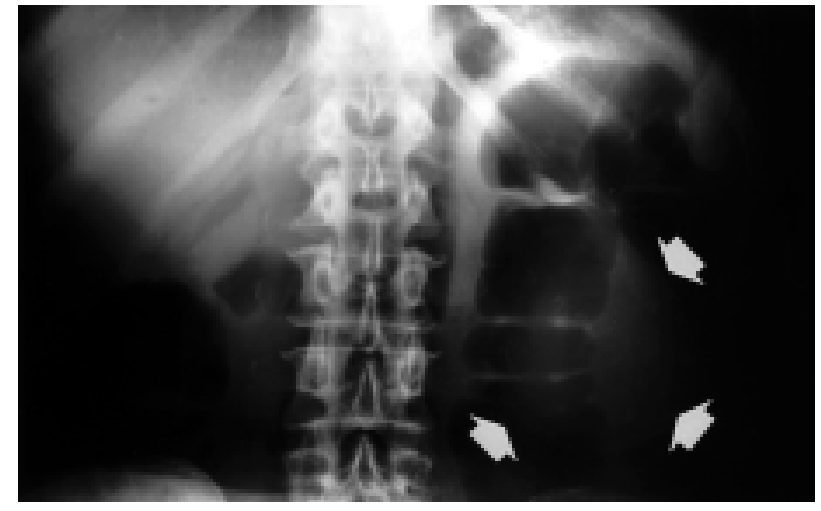

FIGURA 1. Calcificación redondeada proyectada sobre silueta renal izquierda de aprox. $8 \mathrm{~cm}$.

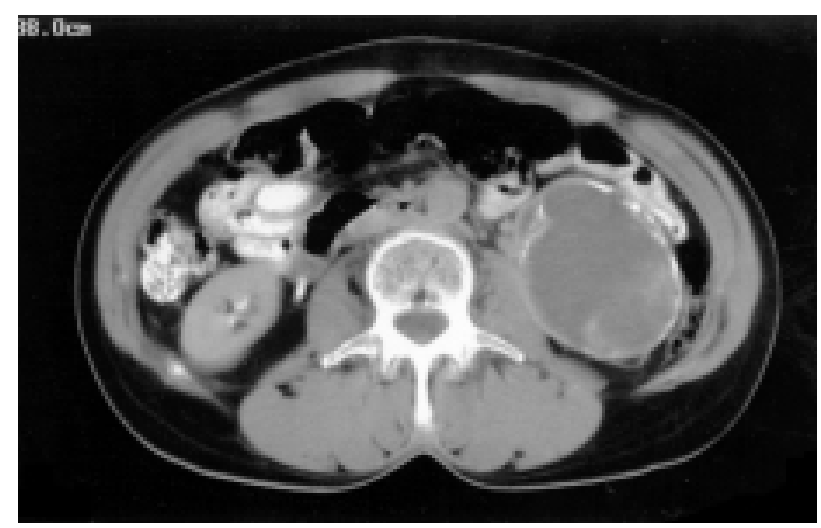

FIGURA 2. TAC abdominal: masa heterogenea tipo II de Bosniak.

fitica, bien delimitada, con aspecto macroscópico de quiste simple muy bien encapsulado lo que facilitó su extirpación. No se evidenciaron adenopatías macroscópicas. Se realizaron biopsias múltiples del tejido circundante.

El informe de anatomía patológica describió la presencia de un carcinoma renal en el interior de una formación quística con múltiples focos hemorrágicos, con extensas áreas de necrosis, siendo el grado histológico de Fuhrman tipo II.

En la unidad de investigación de biología molecular de nuestro hospital se realizó un análisis inmunohistoquímico y del DNA tumoral. Se puso de manifiesto una mayor expresión de los marcadores de proliferación celular activa PCNA (proliferating cell nuclear antigen) y del oncogen $K$-ras, usando el método de la Streptavidina-biotina, utilizando anticuerpos monoclonales.

A nivel del cromosoma 3 se evidenció alteraciones en la región del $3 p$, existiendo un disba- 
lance alélico y más concretamente inestabilidad de microsatélites (presencia en el DNA del tumor tras la amplificación por PCR de fragmentos nuevos que no están presentes en el producto de PCR generado por el DNA del tejido normal) para el marcador D3S1766 4 .

El disbalance alcanzó el 38\%, en diversas publicaciones se considera disbalance alélico desde el 30 al $50 \%{ }^{4-7}$. Este hallazgo se obtuvo mediante el sistema de electroforesis capilar ABI PRISM 310 Genetic Analyzer PE Applied Biosystems. Se midió la altura de los picos de ambos alelos del tejido tumoral (T) y normal (N) y el ratio de disbalance alélico (DA) obteniéndose de la siguiente forma ${ }^{5}$ :

$\mathrm{DA}=$ (Altura alelo largo $\mathrm{T} /$ Altura alelo corto $\mathrm{T})$ / (Altura alelo largo N / Altura alelo corto N).

$\% \mathrm{DA}=1$-DA X100

El curso post-operatorio cursó sin incidencias siendo dada de alta hospitalaria a los 5 días. El seguimiento de la paciente a las 4 semanas y a los 6 meses después de la cirugía no evidenció ni alteración analítica alguna, así como evidencias de recurrencia local o sistémica de la enfermedad. Actualmente la paciente continúa siendo revisada cada 6 meses en consulta externa con total normalidad.

\section{DISCUSIÓN}

Los tumores malignos del parénquima renal suponen alrededor del $2 \%$ de todos los nuevos casos de cáncer y de muerte por año, con un rango entre 20.000 y 30.000 nuevos casos al año. Varios factores ambientales han sido implicados en la etiología del carcinoma renal, ocupacionales, hormonales, celulares y genéticos se pueden considerar como influyentes en el desarrollo de esta neoplasia.

No existe una clara asociación entre el carcinoma renal y la exposición a radiaciones ionizantes. Actualmente no existe una evidencia clara de que estos tumores sean inducidos por la radiación. Después de los efectos radiactivos como consecuencia de los ataques atómicos de Hiroshima y Nagasaki, se realizaron varios estudios que intentaron evidenciar la relación de la exposición a radiaciones con el incremento de mayor tasa de tumores sólidos.

El accidente nuclear de Chernobyl en Ucrania, en abril de 1986 tuvo como consecuencia la expo- sición a radiaciones ionizantes a la población del área. El Cesium $137\left({ }^{137} \mathrm{Cs}\right)$ constituye el 80-90\% de la exposición de esta población. Este radionúclido se concentra y elimina por vía renal y el $90 \%$ de su forma más lábil se excreta por vía urinaria.

Romanenko y cols. en una reciente publicación hace hincapié en la posible relación entre el desarrollo del carcinoma renal y la diferente exposición a radiaciones ionizantes después del accidente de Chernobyl. El trabajo evalúa los hallazgos histopatológicos, así como los cambios inmunohistoquímicos, centrándose en marcadores de proliferación celular activa como el PCNA (proliferating cell nuclear antigen) y el oncogen $K$-ras, en un grupo de 236 pacientes ucranianos. Se establece un grupo control de 112 pacientes españoles con carcinoma renal.

Este trabajo describe por primera vez los hallazgos histológicos encontrados en los cánceres renales de la población ucraniana, expuesta durante más de trece años a bajas dosis de radiación ionizante en las zonas contaminadas. Los cambios histológicos más significativos de los pacientes ucranianos fueron alteraciones a nivel nuclear, presencia de cambios sarcomatoides y alteraciones inflamatorias peritumorales.

Recientes estudios han demostrado que la expresión del PCNA se correlaciona con los tipos histológicos del carcinoma renal, así como su hiperexpresión sugiere una posible influencia de las radiaciones ionizantes, con los resultados del trabajo de Romanenko ${ }^{1,2}$.

En cuanto al papel de los oncogenes y en particular los de tipo ras ( $H$-ras, $N$-ras, $K$-ras) en el desarrollo del carcinoma renal aún no ha sido del todo clarificado. Algunos estudios sugieren que el oncogen K-ras pudiera ser esencial en la proliferación y rápida progresión de los carcinomas renales. La moderada o severa nefropatía post-radiación parece estar asociada a una mayor expresión de este oncogen, en los pacientes expuestos a radiaciones ionizantes.

Vogelzang y cols. realizaron una revisión de la literatura valorando la posible inducción de carcinoma renal como consecuencia de los efectos de la radioterapia. Todos los pacientes de su serie que desarrollaron un carcinoma renal, lo hicieron tras 25 a 35 años después de la radioterapia, por lo que aconsejan un seguimiento de estos pacientes ${ }^{3}$. 
En nuestra paciente destacaba el antecedente de la exposición a radiaciones ionizantes tras el accidente de Chernobyl en el año 1986. Cada día atendemos en nuestros hospitales a pacientes de distintas áreas geográficas, por lo que el conocimiento de determinados factores de riesgo nos deben agudizar la sospecha de ciertas patologías. Por otro lado, la sobreexpresión de los marcadores de proliferación celular (PCNA) y del oncogen $K$-ras parecen confirmar el posible papel de la exposición a radiaciones ionizantes durante tanto tiempo.

\section{REFERENCIAS}

1. ROMANENKO A, MORELL-QUADRENY L, NEPOMNYASCHY V, VOZIANOV A, LLOMBART BOSCH A.: Pathology and proliferative activity of renal cell carcinomas (RCCS) and renal oncocytomas in patients with different radiation exposure after the Chernobyl accident in Ukraine. Int $J$ Cancer 2000; 87: 880-883.

2. ROMANENKO A, MORELL-QUADRENY L, NEPOMNYASCHY V, VOZIANOV A, LLOMBART BOSCH A: Radiation sclerosing proliferative atypical nephropathy of peritumoral tissue of renal cell carcinomas after the Chernobyl accident in Ukraine. Virchows Arch 2001; 438 (2): 146-153.
3. VOGELZANG NJ, YANG X, GOLDMAN S, VIJAYAKUMAR S, STEINBERG G.: Radiation induced renal cell cancer. J Urol 1998; 160: 1.987-1.990.

4. THIBODEAU SN, BREN G, SHAID D.: Microsatellite instability in cancer of the proximal colon. Science 1993; 260 (5109): 816-819.

5. DOLL JA, ZHU X, FURMAN J et al.: Genetic analysis of prostatic atypical adenomatous hyperplasia (adenosis). Am J Pathol 1999 sep; 155 (3): 967-971.

6. SCHNEIDER A, BORGNAT S, LANG H et al.: Evaluation of microsatellite analysis in urine sediment for diagnosis of bladder cancer. Cancer Res 2000; 60: 4.617-4.622.

7. VELICKOVIC M, DELAHUNT B, STÖRKEL S et al.: VHL and FHIT locus loss of heterozygosity is common in all renal cancer morphotypes but differs in pattern and prognostic significance. Cancer Res 2001; 61: 4.815-4.819.

Dr. A. Blanco Espinosa

C/ Isla Madeira, 2 - 3ㅇ A

14011 Córdoba

(Trabajo recibido el 27 febrero de 2002) 